\title{
Gender-based Teaching Strategies to Improve the Students' Communicative Competence: Study Case
}

\author{
Daniel Fernando Buenaño Ortiz, Ruth E. Infante-Paredes, Cristina Jordán, Cristina Páez- \\ Quinde \\ Universidad Técnica de Ambato
}

\begin{abstract}
The study is aimed to assess the relationship of Gender-Based Teaching Strategies (GBTS) and how male and female EFL understudies improve their Communicative Competence (CC). This was an experimental investigation in which a mock pre and post-test were applied to assess the CC elements as: grammatical, textual, functional, and sociolinguistic. To evaluate those elements, GTBS were applied inside the classroom such as: brainstorming, discussions, role-plays, and storytelling. The subjects of the examination were the sixth and eighth-semester students of English Language Career at Universidad Técnica de Ambato. The study population comprised 34 students of eighth semester as the experimental group (EG) and 13 students from sixth semester as the control group (CG). Wilcoxon' signed-rank test contributed to find the relationship between GBTS and the CC. Pyramid technique was used to form three groups of female students, two groups of mixed students, and one group of male students inside the classroom. The results are that female got an improvement of 0,4\% with Brainstorming, 0,9\% with Storytelling and Role-plays, and $1,1 \%$ with Discussion. Male got an improvement of 0,2\% with Brainstorming and Storytelling, 0,7\% with Role-plays and Discussion. Mixed got an improvement of 0,8\% with Brainstorming, 0,1\% with Storytelling, $1 \%$ with Role-plays, and 1,2\% with Discussion.
\end{abstract}

\section{Introduction}

At present, the use of the English language is becoming more and more necessary to be able to communicate in a demanding world that is in constant change due to globalization. In 2016, the Ministry of Education of Ecuador issues a new curriculum where it has been tried to establish clear learning outcomes for the ideal profile of the graduate citizen in terms of the ongoing process of developing social, intellectual and personal skills through all the subjects including English, [19]. Unfortunately it is decontextualized to the reality of the children of pre-kinder, kinder, primary and high school education. By reducing hours of English, grammatical, textual, functional, and sociolinguistic elements of the Communicative Competence (CC) are not achieved. In Ecuador, the Communicative Competence is limited because teachers apply traditional methodologies which consist of using books provided by the Ministry of Education, applying strategies without considering the students' needs, such as gender (men, women, and mixed) preferences.

The term of communicative competence clearly establishes the relationship of two words that when combined result to the ability of an individual to be able to communicate. One of the most important features is that we are human beings and what differentiates us from other animals is the language; from the moment, we are born, people use it to communicate with the world around us and through him we convey our ideas, thoughts, feelings and emotions. But the language not only serves as a means of communication and transmission of information and knowledge, but also through the beings we interpret our world, we classify and tidy up the reality that surrounds us.

The lack of knowledge and the limited use of Gender-Based Teaching Strategies in the development of students' communicative competence is a problem that arises for several reasons, mainly due to the non-application of appropriate Gender-Based Teaching Strategies by teachers which produces a low degree of simple and complex grammatical forms as well as inappropriate vocabulary. Consequently, this problem is framed in divisions of different social groups within the context that is developed and by the scant updating of information on new social and educational trends.

The scarce exposure in the educational curriculum on the teaching process based on Gender Based Teaching Strategies (GBTS) is a real problem when teaching a language. Therefore, traditional ways of teaching generate a socio-educational destruction of students which produces shortened stretches of language as well as irrelevant organization of ideas and cohesive devices, since these are always related to the growth and development of communication, but tend to be unsuccessful when they are following the same pattern without taking care of the new social and cultural paradigms of such a way that in many occasions the production and performance in tasks between women and men can be seen in an isolated way. 
On the other hand, the poor dissemination of Gender-Based Teaching Strategies in the production of school materials is another of the problems faced by teachers generating inaccurately as well as inappropriate use of language. Therefore, there are other conceptions about what is considered "useful" when choosing texts or materials, generating and developing poor communicative competencies between students at the moment of using the language to convey meaning due to the classroom speaking tasks are inappropriate because they are a little useful for enhancing the speaking development of students. Consequently, there is a non-effective student communication which leads to serious problems at the moment of asking students to communicate among them.

The application of GBTS has become a productive research for Language Teaching (LT). This is the focal thought behind the principles of competences in English. According to the Ministry of Education and in this way, it is the objective for the Ecuadorian Institutions. In this sense, Ecuador, in the same way as other different nations around the globe, has endeavored activities, for example, enhancing access to education, in any case, this has not been sufficient to improve Communicative Competence in students from different levels of Education. Institutions are viewed as one of the social spots for the social interaction, but it has not been enough for being competent with the language for this reason it is necessary to implement these strategies in the teaching framework.

Within a society there is always the aspect of social bond that causes the influences of different types, they can be good or bad among students, which is caused by the Lack of training in Gender-Based Teaching Strategies by teachers because some of them continue using the traditional methods in class which generates inappropriate contribution, 18 interaction, and negotiation between speakers where there are few opportunities for real and genuine communication. This becomes a great disadvantage for language learners because there is a limited interaction among them that do not let to improve the oral production and be able to transmit ideas and negotiate meaning.

The inapplicability of teaching strategies, techniques and activities based on gender, the scarce exposure in the educational curriculum, the scarce diffusion of Gender-Based Teaching Strategies in the production of school materials, and the lack of training on the part of teachers in the face of gender teaching strategies would produce low degree of simple and complex grammatical forms as well as inappropriate vocabulary, shortened stretches of language as well as irrelevant organization of ideas and cohesive devices, inaccurately as well as inappropriate use of language, and inappropriate contribution, interaction, and negotiation between students. On the other hand, if there is a change from traditional to new teaching approaches for instance Gender-Based Teaching Strategies, the Communicative Competence will improve due to the fact that it is a learner-centered approach which focus is on meaning rather than on form that allows the learner to develop meaningful tasks.

The main purpose of this study was to determine the relation between Gender-Based Teaching Strategies (GBTS) and the Communicative Competence. This research provides information about how these Strategies enhance the CC. It was conducted due to the necessity to help students improve their CC. To develop this research project a pre-test was carried out. It was based on the criteria provided by FCE mock exam. During the test, students were assessed on what they can do according to the indicators proposed by the Common European Framework. The results obtained from the pre-test showed that students had problems when communicating properly and according to their level.

The implementation of the proposal which consisted of a compilation of lesson plans lasted one month. Once it had finished, a post-test was conducted to determine if the GBTS improve the Communicative Competence or not. A rubric was used in order to provide a more objective assessment of students' performance. This rubric evaluated the Communicative Competence under the following criteria: Grammar and Vocabulary, Discourse Management, Pronunciation and Interactive Communication. The results obtained after the implementation of Gender-Based Teaching Strategies demonstrate that it surely enhances the Communicative Competence. Students notably improved their pronunciation and interaction between each other.

\section{State of the Art}

Currently there is a great deal of discussion of which would be the most appropriate way for a student to learn this language and how to use it and thus fulfill its main objective which is to communicate with other people. Furthermore, there is still a remarkable level of agreements between theorists. Fahrutdinova and Vasileva [18], showed a satisfactory evidence in Russia about (82\%) of the effectiveness of competence based and interactive approaches on the formation of foreign language communicative competence (linguistic, discursive, sociocultural, strategic, social, and sociolinguistic) of students.

Tanzil, [29] explores the correspondence of Gender Based Communicative Strategies of male and female EFL students which particularly breaks down the accompanying issues. Gender-Based Teaching Strategies are procedures or resources used by the teaching agent to promote meaningful learning, based on socially built jobs, practices, exercises, and 
properties that a general public think about fitting for people. Along these lines, its roles are the consequence of the participation among individuals and their environment and they give individuals signs about what sort of lead is acknowledged to fit for what sex. Reasonable gender roles are portrayed by an overall population's feelings about differences between genders. The term gender alludes to the financial matters, social, political and social qualities and openings, related with being male and female. In many social orders, people vary in the exercises they attempt, in access to and control of assets, and in cooperation in basic leadership. Furthermore, gender is an idea that people make socially, through their collaborations with one another and their surroundings, yet it depends vigorously upon organic contrasts between men and women. Since people make the idea of gender socially, it is alluded as a social development [3]. In other words, being interaction a social indicator it is necessary to apply Gender-Based Teaching Strategies such as brainstorming, discussions, storytelling, and roleplays.

\subsection{Gender-Based Teaching Strategies}

Gender is worked in individual, interactional, and fundamental ways to deal with make environmental objectives and openings that works better with men more than women [3]. Furthermore, does not impact families' lives in disconnection. In addition, its roles rely upon the particular wants that individuals, gettogethers, and social requests have of individuals subject to their sex and reliant on each overall population's characteristics and feelings about sex. Along these lines, its roles are the consequence of the participation among individuals and their environment and they give individuals signs about what sort of lead is acknowledged to fit for what sex. Reasonable gender roles are portrayed by an overall population's feelings about the differences between the genders. Truly it is across the board that diverse qualities, jobs, obligations and qualities among people in the public eye directed by various social organizations are controlled by their gender roles which are adequate and not variable in society and it is a result of their natural contrasts which make women and men, in charge of their helper status in people in general field [3].

Likewise, this phenomenology existing regularly which include the issues of sexual orientation partition, abuse, awkward nature and foul play in the general population coordinated by standards and qualities. As indicated by Matthews [30], the idea of gender offers acknowledgment to the way that each known society recognizes ladies and men. Along these lines the term "gender" is an efficient method for understanding men and women socially and the designing of connections between them.
The term gender alludes to the financial matters, social, political and social qualities and openings, related with being male and female. In many social orders, people vary in the exercises they attempt, in access to and control of assets, and in cooperation in basic leadership. Furthermore, gender is an idea that people make socially, through their collaborations with one another and their surroundings, yet it depends vigorously upon organic contrasts between men and women. Since people make the idea of gender socially, it is alluded as a social development [3]. Then, the social development of gender is shown by the way that people, gatherings and social orders credit specific characteristics, statuses, or qualities to people due to their sex, yet these attributions vary crosswise over social orders and societies, and over time inside a similar society.

On the other hand, based on the concepts above of Gender and Teaching Strategies the author will propose that Gender-Based Teaching Strategies are procedures or resources used by the teaching agent to promote meaningful learning based on socially built jobs, practices, exercises and properties that a general public think about fitting for people.

Brainstorming is a procedure by which a gathering endeavor to discover a solution(s) to an explicit issue by storing up thoughts immediately [26]. While some examination has observed brainstorming to be ineffectual, this appears to be all the more an issue with the exploration itself than with the conceptualizing instrument [22]. Another concept that refers to brainstorming is the procedure of free reasoning and creating thoughts without being bound by restrictions [16]. This strategy is carried out based on the premise that a group of people generates more than just one [27]. It is a profoundly powerful strategy for augmenting bunch imaginative potential, not exclusively to create thoughts yet additionally to figure out which thoughts are destined to prevail in an explicit region of intrigue [6]. It is critical to design the meeting to generate innovative ideas previously actualizing it in the classroom. As sketched out beneath, you should think about the qualities, challenges what's more, hindrances when planning the session. It is a meeting or group dynamics that frequently performed by a moderator in order to favor the generation of new ideas or the improvement of existing [25].

Another strategy is Discussions which is appropriate to encourage various course objectives. As expressed by Lowman, [23] when he said it helps elucidating content, showing normal reasoning, and featuring emotional decisions. In addition, is especially powerful at expanding understudy inclusion and dynamic learning in classes. Discussions are successful in building up understudies' reasoning abilities and larger amount adapting, for example, application, examination, combination, and assessment [10]. 
Discussions can enable understudies to gain better relational abilities as they figure out how to introduce their thoughts obviously and quickly [13] it additionally gives chances to rehearse tuning in to, and following what, others are stating. In expansion, discussions can add to understudies' emotional advancement by expanding their enthusiasm for an assortment of subjects, illuminating their qualities, and helping in perceiving - and maybe changing a few frames of mind. As a showing strategy, discussion licenses understudies to be dynamic in their very own realizing, which increments their inspiration to learn and makes the procedure more fascinating. Lastly, discussion gives criticism to teachers about their understudies' securing of learning through questions, remarks, elaborations, and avocations. This cooperation enables teachers to plumb the profundities of understudies' understanding. To guarantee that understudies consider talks important, you may need to change your current reward framework [12]. On the off chance that you will review understudies for investment, clarify how. Think about selfassessments, peer to peer assessments, and rubrics that typically portray expected and unsuitable dimensions of investment [17].

Storytelling is also considered as a strategy for sharing and deciphering encounters. Berger and Luckman, [7] say human life is narratively established; people develop their lives and shape their reality into homes regarding these groundings and recollections. Storytelling can be versatile for all ages, forgetting the thought of age segregation. Storytelling can be utilized as a strategy to show morals, values and social standards and differences.

Narration and story-telling have been broadly used as a plan strategy. Bergeron and Rouse [8] proposed a narration-based plan strategy by investing the theoretical chronicled societies and explicit situations with undertones to extend the group of spectator's experiences. The structure talking points of Buchanan [31] states that the communicating capacity of configuration is one of the most imaginative strategies. Also, story-telling can be used as both input and output in user experience plan. As sources of info, stories are used during information accumulation to direct users or let them depict their issues and feelings as stories, and the gathered information are the reason for the ensuing outputted elaboration [9].

As outputs, the role setting, situation foundation, and storyboards are connected into torment point needs, issue introduction and idea proposition, to make the marvels and issues increasingly express and concrete. In the interim, the plan ideas are blended into situation storyboards to improve the convincingness. Up until now, numerous story-based techniques, for example, user story maps, user story spry strategies, and storyboards, have been broadly connected to the structure flowchart. For example, user story maps can be used to picture students' voyages and help specialists to correctly investigate the user flowchart nodes [28]. The user story agile technique can be utilized to proficiently gather user stories if there should be an occurrence of difficult to reach student correspondence, and to mastermind, organize, plan, oversee and test the composed user stories [15].

Concerning contextual investigations, many structure research groups have endeavored to consolidate portrayal; situations what's more, inquire about courses and apply such blend into all pieces of the plan flowcharts. For example, The Institute of Innovation from the Polytechnic University of Milan used a guide narrating technique to record the lives of the elderly and discovered the interest torment focuses, and opportunity focuses are beginning from the social hubs of the older, in this way incompletely structuring the elderly network administrations. An Italian plan group SDS independently introduced the structure components as pictures, furthermore, made the themed stories as blend and associating with explain the idea articulations.

Role-play is another type of strategy that enables understudies to investigate practical circumstances by connecting with other individuals in an oversaw path so as to create involvement and preliminary distinctive procedures in an upheld domain. Contingent upon the aim of the action, members may assume a job like their own or could have the contrary impact of the discussion or connection.

Constructivist approaches to deal with learning and has been pushed for quite a while. Be that as it may, educating depending on transmission learning and down to earth work have frequently neglected to acknowledge seeks after constructivist learning [1].

This is especially valid for students where an absence of qualified educators, books and down to earth assets brings about much repetition learning with almost no gathering work and connection between understudies [20]. Along these lines it merits considering progressively intuitive strategies, for example, show that include understudies learning methods and procedures through scripted and extemporized plays, pretends and move/emulate. Dramatization based instructional method in education is a piece of a social constructivist scene of learning whereby understudies' individual and aggregate understandings of ideas might be widened, tested, or potentially affirmed through their understandings of pictures, activities and stories created during dramatization-based assignments [11], [31]. Braund [11] offers three different ways of dramatization that helps learning process: about ideas, about the nature of science and about science and society. To the extent science is worried there is proof that dramatization has helped learning. It has been proposed that this strategy pretends give commitment in manners that give prompt access to complex natural 
thoughts. Aikenhead [2] claims that stories using dramatization help students make outskirt intersections between students. This is especially significant in Ecuadorian halls where information can be an unmistakable piece of students' conceptualization of their general surroundings, one that contentions with the objective ideas to be instructed (Langer 2011; Semali 1999).

Dramatization is especially ground-breaking in helping understudies acknowledge manners by which speculations are built, challenged, and approved. The plays depicted by Braund [11] are models in the zone of development. As per Hendrix et al. [31], 'exercises related with imaginative dramatization for example, pantomine and improvisation can make a value-based learning pathway so as to help understudies manufacture further comprehension of ideas.' The 'value-based pathway' picked for this examination was for understudy instructors to use role-play, where students carry on with their bodies and restricted props, the groupings, structures and procedures related with natural wonders. Physical role-plays can be viewed as instances of practically equivalent to learning. Harrison and Treagust [21] note the specific intensity of show as an option in contrast to different types of analogs, for example, outlines, PC reproductions, and practical work since activities include closer personal interaction with content. As indicated by McSharry and Jones [24] role-plays, both physical and scripted, are viable learning tools because they 'provided: an alternate account from composed media, a feeling of possession through creation and execution, ways into discussions and dialog of touchy issues and physical experience through which dynamic material is made understandable.

\subsection{Communicative Competence}

Fahrutdinova and Vasileva [18] gave careful consideration to the planning of expertly skilled specialists in the field of teaching exercises, specifically preparing of future language educators, by applying intelligent techniques for instructing. Foreign language communicative competence is seen by the theorist as the premise of expert capability of future foreign dialect educator. The term «communicative competence» includes two words, the blend of which implies «competence to communicate». This straightforward lexicosemantical investigation reveals the way that the focal word in the syntagm «communicative competence» is the word «competence». «Competence» is a standout amongst the most dubious terms in the field of general furthermore, connected semantics. First experience with phonetic talk has been generally associated with Chomsky [14] who in his exceptionally influential book «Aspects of the Theory of Syntax» drew what has been today seen as a great refinement between competence (the monolingual speaker-audience's learning of language) and performance (the real utilization of language in genuine situations).

At roughly a similar time and for comparative reasons, Bachman [4] proposed utilizing the term «communicative language ability», asserting that this term consolidates the implications of both dialect proficiency and informative capability. Bachman defined communicative language ability as an idea contained learning or capability and limit with regards to proper utilization of learning in a logical informative dialect use. In expounding on this definition, Bachman committed special regard for the part of dialect use - that is, the way how dialect is utilized to achieve a specific informative objective in a specific situational setting of correspondence. As indicated by [5], numerous characteristics of language users for example, some broad attributes, their topical learning, full of feeling schemata furthermore, dialect capacity influence the communicative language ability. The urgent trademark is their language ability which is included two wide areas - language knowledge and strategic competence.

Language Knowledge comprises of two primary segments - organizational knowledge and pragmatic knowledge which supplement each other in accomplishing successfully the language use. Organizational Knowledge in Bachman and Palmer's model, organizational knowledge is made of capacities occupied with a command over formal language structures, i.e. of grammatical and textual knowledge. Grammatical knowledge incorporates a few rather autonomous territories of learning, for example, knowledge of vocabulary, morphology, syntax, phonology, and graphology. They empower acknowledgment and creation of linguistically right sentences and additionally cognizance of their propositional content. Textual knowledge empowers cognizance and generation of (talked or composed) writings. It covers the information of traditions for joining sentences or expressions into writings, i.e. knowledge of cohesion (methods for stamping semantic connections among at least two sentences in a composed content or expressions in a discussion) also, information of rhetorical organization (method for creating story writings, portrayals, correlations, classifications and so forth.) or conversational organization (conventions for starting, keeping up and shutting discussions).

Pragmatic knowledge alludes to capacities for making and interpreting discourse. It incorporates two areas of knowledge: functional knowledge for communicating satisfactory and for deciphering the illocutionary intensity of articulations or talk and sociolinguistic knowledge for making and interpreting language utterances which are fitting in a specific setting of language use.

Toward the finish of this illustrative portrayal of Bachman and Palmer's model of Communicative 
Language Ability, one can't however, conclude that this model is increasingly mind boggling, more complete and much clearer than the model of Canale and Swain. It is best because has a direct result of its nitty gritty and at the same time hierarchical depiction of essential parts of Communicative Competence.

\section{Methodology}

The research consisted of the application of an experiment in which the subjects were students from sixth (control group CG) and eighth (experimental group EG) semesters of the Languages Major of the Universidad Técnica de Ambato. The experimental group was divided in six groups as the following: 3 groups of women only, 2 groups of women and men (mixed group), and 1 group of men only to apply Gender-Based Teaching Strategies. A pre-test was administered to both $\mathrm{CG}$ and $\mathrm{EG}$ groups to diagnose the level of the students' communicative competence, after that, gender-based teaching strategies were applied to the EG only and finally a post-test was administered to both CG and EG.

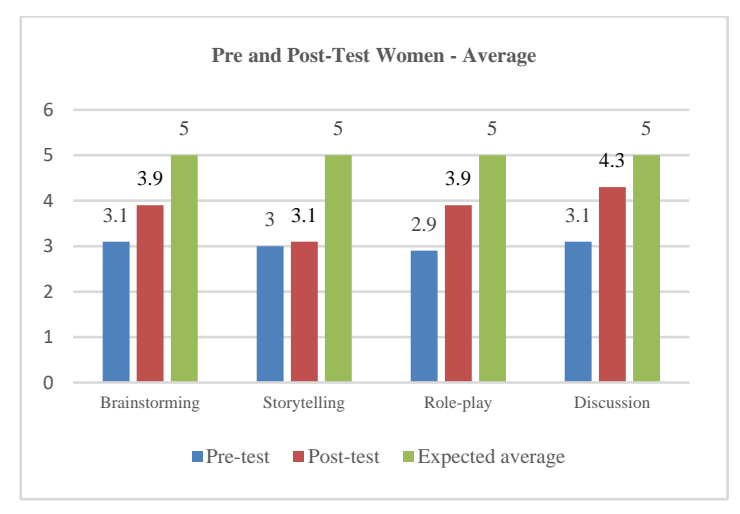

Figure 1. Pre and Posttest students Source: Experimental Group-Women

The graphic shows the results of the pre-test and post-test of women's group performance. The average score of the pre-test was 3,3 and there was an expansion in the last score on account of the utilization of Brainstorming getting 3,7 and thinking about the elements of the Communicative Competence that were assessed in the speaking test, it is clear that understudies had enhanced in their exhibitions and the systems helped them to deal with a decent level of control of syntactic structures and vocabulary because of the use of the new strategy. It also demonstrates that in the pre-test understudies got an average of 3,2 while after the utilization of the posttest the outcomes show there was an augmentation getting as a last outcome 4,1 in Storytelling. It alludes to the capacity understudies need to keep an intelligent stream of dialect. The ability to create thoughts with adequate elaboration and subtleties. In this manner, as it appeared expected normal there was not satisfied in understudies' execution on the grounds that there were not broadened stretches in their reactions and there were no reasonable association of thoughts, so it is vital to apply a new Methodology to help communicators who will indicate expanded reactions and thus better commitments with a wide scope of durable gadgets.

A rubric taken from Cambridge Assessment criteria for FCE was used as the instrument to evaluate students' communicative competence. The rubric considers criteria such as Grammar and Vocabulary, Discourse Management, Pronunciation, and Interactive Communication with a 1-3-5 score. Once the rubric was applied before and after the implementation of Gender-Based Teaching Strategies, EG students notably improved their communicative competence regarding Pronunciation and Interactive Communication. Also, there was a little improvement in Grammar and Vocabulary as well as in Discourse Management.

In view of the account's investigation, the estimation of the Communicative Competence was created thinking about the criteria of the rubric from the FCE examination so as to give a precise method for surveying understudies. Four elements of Communicative Competence were evaluated such as: Grammar and Vocabulary, Discourse Management, Pronunciation, and Interactive Communication with the application of brainstorming, role-plays, storytelling, and discussion.

\subsection{Final pre and post-test scores experimental group}

\section{Analysis and Interpretation:}

The outcomes from Table 1 demonstrate a correlation between the three gatherings (ladies, men and blended) there was an expansion in the last scores of the Grammar and Vocabulary gotten by the understudies we can see that the procedures utilized in the classroom functioned admirably basically with the blended gathering that is the reason they got 0,8 ; with a lower review are ladies with a score of 0,4 ; lastly the gathering of men with the most minimal review 0,2 . It implies that understudies from ladies and men need to practice to enhance their fitness.

In Discourse the executives the table 1 demonstrates an examination between the three gatherings (ladies, men and blended) there was an expansion in the last scores gotten by the understudies we can see that the procedures utilized in the classroom functioned admirably for the most part with ladies that is the reason they got 0,9 , with a comparable review are men with a score of 0,2 , and the blended gathering with the least grade 0,1 . It implies that understudies from men and blend need to practice to enhance their talk. 
Table 1. Final pre and post-test experimental group

\begin{tabular}{ccccc}
\hline $\begin{array}{c}\text { Elements of } \\
\text { the C. C. }\end{array}$ & Women & Men & Mixed & $\begin{array}{c}\text { Class } \\
\text { Average }\end{array}$ \\
\hline $\begin{array}{c}\text { Grammar and } \\
\text { Vocabulary }\end{array}$ & 0,4 & 0,2 & 0,8 & 0,5 \\
\hline $\begin{array}{c}\text { Discourse } \\
\text { Management }\end{array}$ & 0,9 & 0,2 & 0,1 & 0,4 \\
\hline Pronunciation & 0,9 & 0,7 & 1 & 0,9 \\
\hline $\begin{array}{c}\text { Interactive } \\
\text { Communication }\end{array}$ & 1,1 & 0,7 & 1,2 & 1 \\
\hline
\end{tabular}

Source: Pre-test scores - Experimental Group-Mixed

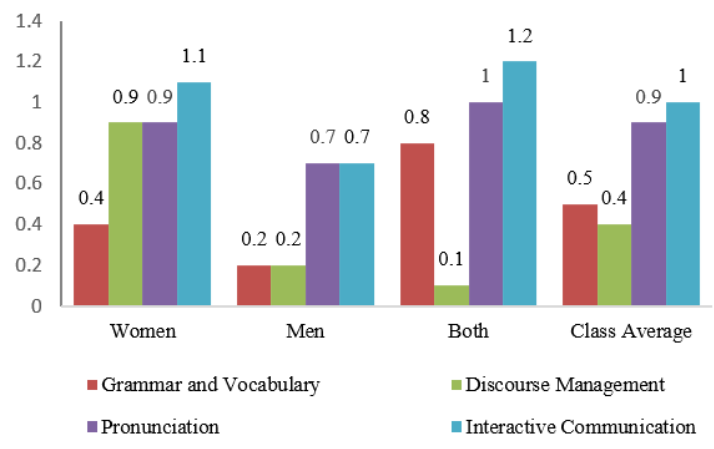

Figure 2. Final pre and post-test experimental group Source: Pre-test scores - Experimental Group-Mixed

In Pronunciation the Table 1 demonstrate a correlation between the three gatherings (ladies, men and blended gathering) there was an expansion in the last scores acquired by the understudies we can see that the systems utilized in the classroom functioned admirably fundamentally with the blended gathering and ladies that is the motivation behind why the scores are comparable both got 1,0 , and ladies with a score of 0,9 , lastly the gathering of men with the most minimal review 0,7 . It implies that men need to practice to enhance their articulation.

In Interactive Communication the Table 1 demonstrate an examination between the three gatherings (ladies, men and blended) there was an expansion in the last scores acquired by the understudies we can see that the procedures utilized in the classroom functioned admirably for the most part with the blended gathering and ladies that is the motivation behind why they got 1,2 , while ladies had a score of 1,1 , lastly the gathering of men with the least grade 0,7 . It implies that men and men require additional training to enhance their association.

The primary reason for this exploration was to upgrade the Communicative Competence of understudies that is the reason the examination of the pre-test and post-test demonstrates that after the utilization of Gender-based showing systems their execution enhanced because of the undertakings that were thought about in each class helped them to talk better, unmistakably the normal score (5) was not achieve, but rather the methodologies and exercises utilized in the classroom helped them and with more practice they will satisfy the target.

\section{Results}

\subsection{Pre and Post-test Results Control Group}

In view of the chronicles' investigation, the estimation of the informative capability was created contemplating the criteria of the rubric from the FCE examination.

Table 2. Pre and Post-Test

\begin{tabular}{|c|c|c|c|c|}
\hline 7th & 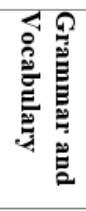 & 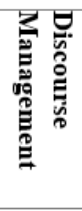 & 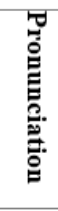 & 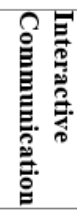 \\
\hline Pre-test & 3 & 3 & 2,9 & 3,1 \\
\hline Post-test & 3,3 & 3,4 & 3,3 & 3,5 \\
\hline Expected average & 5 & 5 & 5 & 5 \\
\hline
\end{tabular}

Source: Pre-test scores - Experimental Group

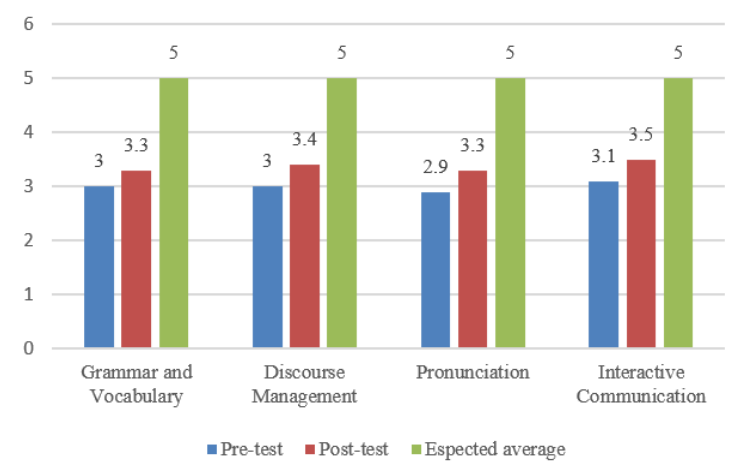

Figure 3. Pre and Post-Test

As it is shown in table 2 the score of the pre-test was 3 whereas after the application of the post-test the score was 3,3. Grammar and Vocabulary were considered as an element of the communicative competence and as it could be observed the variation in the results shown was not big at all due to the fact was not applied in this group. Students showed a good control of simple grammatical forms and vocabulary.

The results from table 2 show that in the pre-test, the students got a score of 3,0 in the pre-test, while in the post-test they obtained 3,4. One of the criteria that were evaluated in speaking was Discourse Management with the purpose of assessing the capacity to produce responses adequately using cohesive devices. However, as the results show this criterion show a regular improvement. The responses produced in the pre-test were characterized by short phrases and frequent hesitation. Students' answers 
were most of the time repeated and there was a limited use of vocabulary, but at the end it changed.

As table 2 demonstrates the final score in pronunciation during the pre-test was 2,9 while after the application of the post-test it increased to 3,3 . Which means that there is not a big improvement. Pronunciation is one of the main factors considered as important in speaking assessing due to the fact it helps to produce intelligible intonation. The results show there was a maximum improvement in students' performance. Students' production was intelligible and had control of phonological features. Hence, it is necessary to continue helping students improve their way of speaking in order to be understood by everyone.

According to the data of table 2, the final score in Interactive Communication was 3,1 corresponding to the pre-test and in the post-test, the average was 3,5. As it is shown, there was not a significant variation in these results. Interactive Communication did not improve at all in this stage owing to its peer practice. This issue is relevant to be evaluated since students need to have the capacity to interact in English appropriately. Students at the beginning maintained simple exchanges with some difficulty that required support and prompting.

\subsection{Elements of the communicative competence pre and post-test comparison experimental and control group}

\section{Analysis and Interpretation:}

The table 3 demonstrates the scores of the exploratory gathering fluctuate in every single one of the criteria considered in talking evaluation. Punctuation and Vocabulary from 3,4 to 3,9 , Discourse Management from 3,3 to 3,7, Pronunciation from 3,3 to 4,2 and Interactive Communication from 3,4 to 4,4 .

The Control amass was additionally surveyed under similar criteria; be that as it may, their enhancement is constrained. In Grammar and Vocabulary, the score differed from 3,0 to 3,3 . Though in Discourse Management from 3,0 to 3,4. So also in Pronunciation from 2,9 to 3,3 . Intelligent Communication from 3.1 to 3,5 .

As indicated by this information, it is quite observed that there is an enhancement in the correlation of the last scores of the pre and post-tests in the Experimental Group after the utilization of Gender-based Teaching Strategies to improve the Communicative Competence. While the outcomes were as not very great not surprisingly in the Control Group because of the reality understudies did not work with these procedures in their open capability.
Table 3. Pre and Post-test

\begin{tabular}{cccccc}
\hline $\begin{array}{c}\text { Elements of the } \\
\text { C. C. }\end{array}$ & \multicolumn{2}{c}{ Experimental } & \multicolumn{2}{c}{ Control } & $\begin{array}{c}\text { Expected } \\
\text { Average }\end{array}$ \\
\cline { 2 - 5 } & $\begin{array}{c}\text { Pre- } \\
\text { test }\end{array}$ & $\begin{array}{c}\text { Post- } \\
\text { test }\end{array}$ & $\begin{array}{c}\text { Pre- } \\
\text { test }\end{array}$ & $\begin{array}{c}\text { Post- } \\
\text { test }\end{array}$ & \\
\hline $\begin{array}{c}\text { Grammar and } \\
\text { Vocabulary }\end{array}$ & 3,4 & 3,9 & 3 & 3,3 & 5 \\
\hline $\begin{array}{c}\text { Discourse } \\
\text { Management }\end{array}$ & 3,3 & 3,7 & 3 & 3,4 & 5 \\
\hline $\begin{array}{c}\text { Pronunciation } \\
\text { Interactive }\end{array}$ & 3,3 & 4,2 & 2,9 & 3,3 & 5 \\
\hline \begin{tabular}{c} 
Communication \\
\hline
\end{tabular} & & 4,4 & 3,1 & 3,5 & 5 \\
\hline
\end{tabular}

Source: Pre and Post-test scores -Experimental - Control Groups

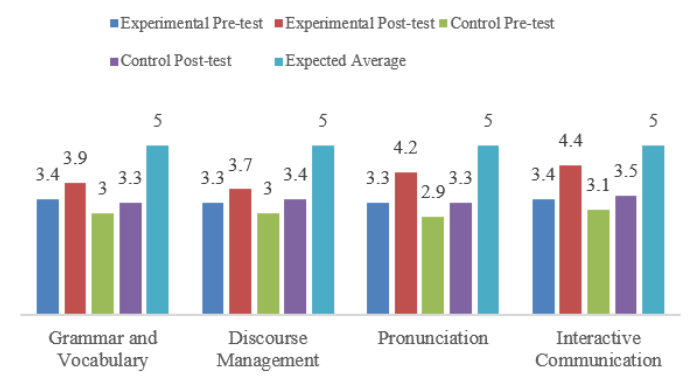

Figure 4. Pre and Post-test

Source: Pre and Post-test scores -Experimental Control Groups

The outcomes acquired from the last normal somewhere in the range of eight and 6th semesters in talking exhibit that understudies got 0,5 and 0,3 in Grammar and Vocabulary which implies that the two gatherings require additional training to enhance this component. In Discourse Management the primary gathering got 0,4 and shockingly the second gathering got a similar score, so plainly both need to work out in this component to enhance their commitment and the generation of extended lengths dialect. In Pronunciation, the two gatherings got 0,9 and 0,4 individually and it demonstrates that exploratory gathering would do well to average and the control assemble need to keep examining. In Interactive Communication exploratory gathering got the best grade which was 1,0 while the control assembles got 0,4 , so it implies that the techniques connected in eight semester worked effectively and in the meantime shoe that 6th semester require a portion of the methodologies to enhance their association.

As it is watched the scores in both pre and posttest from the two gatherings of study were great in trial gathering while control bunch require more help to ace their Communicative Competence. The motivation behind this exploration considers was to improve the Communicative Competence through the execution of Gender-based Teaching Strategies. In any case, this gathering of understudies did not work with this methodology; so consequently, it is fitting to utilize the procedures, strategies, strategy, and exercises that support their oral creation and their capacity to convey. 
As it was an experimental research KolmogorovSmirnov Test was used to determine if the experiment was successful or not and Normality Probabilistic was applied to study the distribution and the symmetry.

Table 4. Ranges

\begin{tabular}{|c|c|c|c|c|}
\hline & & $\mathbf{N}$ & $\begin{array}{l}\text { Avera } \\
\text { ge } \\
\text { range }\end{array}$ & $\begin{array}{l}\text { Sum of } \\
\text { ranges }\end{array}$ \\
\hline \multirow{4}{*}{ 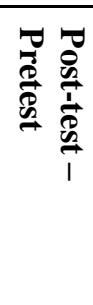 } & $\begin{array}{l}\text { Negatives } \\
\text { ranges }\end{array}$ & $\mathbf{0}^{\mathbf{a}}$ & ,00 & ,00 \\
\hline & $\begin{array}{l}\text { Positives } \\
\text { ranges }\end{array}$ & $4^{b}$ & 2,50 & 10,00 \\
\hline & Drwas & $\mathbf{0}^{\mathrm{c}}$ & & \\
\hline & Total & 4 & & \\
\hline
\end{tabular}

a. Post-test < Pretest

b. Post-test $>$ Pretest

c. Post-test $=$ Pretest

In the range test table it can be seen that the positive ranges in Communicative Competences, 1. Grammar and Vocabulary, 2. Discourse Management, 3. Pronunciation and 4. Interactive Communication, there are positive ranges, that is, the post-test it is greater than the pre-test, considering that GenderBased Teaching Strategies has a relationship with the Communicative Competence of students from the Languages Career at Universidad Técnica de Ambato.

Table 5. Statistics of contrast ${ }^{\mathrm{a}}$

\begin{tabular}{ll}
\hline & \multicolumn{1}{c}{ Post-test - Pretest } \\
\cline { 2 - 2 }$Z$ & $-1,841^{\text {b }}$ \\
Sig. asintót. (bilateral) &, 046 \\
\hline a. Wilcoxon signed sign test \\
b. Based on negative ranges.
\end{tabular}

Source: Hypothesis verification

In the contrast statistic, taking the Wilcoxon test, it can be shown that when $\mathrm{Z}$ is obtained with a value of -1.841 (bilateral) and the value of $p$ is 0.046 , and this is less than 0.05 , the null hypothesis is rejected, so the alternative hypothesis is accepted, that is, Gender-Based Teaching Strategies has a relationship with the Communicative Competence of students from the Languages Career at Universidad Técnica de Ambato.

\section{Conclusions}

The study's main purpose was to determine the relationship between Gender-Based Teaching Strategies with the Communicative Competence of students from Technical University of Ambato. The results to emerge from the data is that Gender-Based Teaching Strategies such as Brainstorming, discussions, role-plays, and storytelling improve the elements of the communicative competence as for example Pronunciation, Interactive Communication, Grammar and Vocabulary and Discourse Management. One of the most striking results is that Discussion allowed students to enhance interaction among them and improve pronunciation greatly. Additionally, the elements of the Communicative Competence such as grammatical which includes vocabulary, syntax, phonology, graphology; textual which includes cohesion and rhetorical organization; functional with ideational, manipulative, heuristic, and imaginative functions and sociolinguistic with dialects, registers, idiomatic expressions, cultural references and figures of speech greatly contribute to detect problems to be solved. The pre and post-tests assessed the elements of the communicative competence before and after the implementation of the Gender-Based Teaching Strategies which shows significant advance in the communicative competence elements such as pronunciation and interactive communication. This lends support to previous findings in the literature for instance a research entitled Analysis of the Teaching Practices at a Colombian Foreign Language Institute and their Effects on Students' Communicative Competence that similarly concluded that certain parts of the understudies' structural and logical skills were likewise upgraded. Additionally, being GTBS important for developing the communicative competence it is crucial for teachers to use them in EFL classrooms since the results have a number of similarities with the findings of the research entitled: A Learning Experience of the Gender Perspective in English Teaching Contexts. One of the main findings was that this reflection likewise prompts suggestions for educators' practices with a gender point of view. As future research it is suggested to apply GenderBased Teaching Strategies to other competences such as strategic to overcome language gaps and achieve conversational fluency and all the students from the Language Career at Universidad Técnica de Ambato as well as in all the Universities in Ecuador and finally why not applying GTBS in all levels of Education such as in Primary and Secondary Schools

\section{References}

[1] Abrahams, I. and Millar, R. (2008). Does Practical Work Really Work? A study of the effectiveness of practical work as a teaching and learning method in school science. International Journal of Science Education. Retrieved from https://www.tandfonline.c om/doi/full/10. 1080/09500690701749305? scroll=topandneedAccess=true

[2] Aikenhead, G. (2001). Integrating Western and Aboriginal science; Cross-cultural science teaching. Research in Science Education, 31, 337-355 
[3] Anon. (2018). Course Material for B.Ed ( First Year). Retrieved from TAMIL NADU TEACHERS EDUCATION UNIVERSITY: http://www.tnteu.in/pdf/c6. pdf

[4] Bachman, L. (1990). Fundamental Considerations in Language Testing. Oxford: OUP.

[5] Bachman, L., and Palmer, A. (1996). Language Testing in Practice: Designing and Developing Useful Language Tests. Oxford etc.: OUP.

[6] Baumgartner, J. (2005). Key factors to successful brainstorming.

[7] Berger, P. L., and Luckman, T. (1991). The social construction of reality. Great Britain: Penguin books.

[8] Bergeron S, Rouse J. (2009). Engaging the Virtual Landscape: Serious gaming environments as tools in historical landscape reconstruction and interpretation. 2009:6-31.

[9] Bleakley A. (2010). Stories as data, data as stories: making sense of narrative inquiry in clinical education. Medical Education. 39(5):534-540.

[10] Bloom, B., Engelhart, M., Furst, E., Hill, W., and Krathwohl, D. (1956). Taxonomy of educational objectives: Handbook I, the cognitive domain. New York: David McKay.

[11] Braund, M. (2014). Drama and learning science: an empty space? British Educational Research Journal, 41(1), 102-121. doi:10.1002/berj.3130

[12] Brookfield, S., and Preskill, S. (2005). Discussion as a way of teaching (2nd ed.). San Francisco: Jossey-Bass.

[13] Cashin, W. E. (2011). Effective classroom discussions. IDEA Paper number 49. , 1-5.

[14] Chomsky, N. (1965). Aspects of the theory of syntax. Massachusetts: Massachusetts Institute of Technology. Coe, R. e. (2014). What makes great teaching. Review of the underpinning research. London: The Sutton Trust.

[15] Cohn M. (2004). User Stories Applied: For Agile Software Development. Addison Wesley Longman Publishing Co. Inc

[16] Cory, T., and Slater, T. (2003). Brainstorming. Techniques for new ideas. Lincoln, NE: iUniverse Inc.

[17] Davis, B. (2009). Tools for teaching (2nd ed.). San Francisco: Jossey-Bass.

[18] Fahrutdinova, R. A., and Vasileva, I. D. (2016). The formation of foreign communicative competence as the basis of professional competence of future teacher of foreign language. Journal of Organizational Culture, Communications and Conflict, 209-214.

[19] Freire Quintana, J., Páez Quinde, M., Núñez Espinoza, M., Narváez Ríos, M., and Infante Paredes, R. (2018). El diseño curricular, una herramienta para el logro educativo /
Curriculum design, a tool for educational achievement. Revi sta De Comunicación De La SEECI, O(45), 75.doi:10.1519 8/seeci.2018.45. 75-86

[20] Hardman, F. Ackers, J. Abrishamian, N. O’Sullivan, M. (2011). Developing a systemic approach to teacher education in sub-Saharan Africa: emerging lessons from Kenya, Tanzania and Uganda. Compare: A Journal of Comparative and International Education. Retrieved from https://www.tandfonline.com/doi/abs/1

[21] Harrison, A. G., and D. F. Treagust. (2006). "Teaching and Learning with Analogies." In Metaphor and Analogy in Science Education, edited by P. J. Aubusson and A. G. Harrison, 11-24. Dordrecht: Springer.10.1007/1-4020$3830-5$

[22] Isaksen, S. G. (1998). A Review of Brainstorming Research: Six Critical Issues for Research. Buffalo: Creative Problem Solving

[23] Lowman, J. (1995). Mastering the techniques of teaching (2nd ed.). San Francisco: JosseyBass. 86 Mathews, L. (1984). Construction of Feminity.

[24] McSharry, G., and S. Jones. 2000. "Role-Play in Science Teaching and Learning." School Science Review 82 (298): 73-82

[25] Michalko, M. (2006). Thinkertoys (A Handbook of Creative-Thinking Techniques (2nd Edition).

[26] Osborn, A. (1954). Applied Imagination.

[27] Rich, J. (2003). Brain Storm: Tap into Your Creativity to Generate Awesome Ideas and Remarkable Results.

[28] Patton J, Economy W P, Fowler F B M, et al. (2014). User story mapping: discover the whole story, build the right product.

[29] Tanzil, H. (2016). Gender-based Communication Strategy. The Asian EFL Journal, 187-202.

[30] Matthews, J.J., (1984). Good and Mad Women. The Historical Construction of Feminity in Twentieth Century Australia. Sydney: George Allen and Unwin.

[31] Buchanan, R., (1992). Wicked Problems in Design Thinking. Design Issues, Vol. 8, No. 2, pp. 5-21. Published by: The MIT Press. http://www.jstor.org/stable/1511637. (Access date: 4 November 2018).

[31] Hendrix, R., Eick, C., and Shannon, D. (2012). The Integration of Creative Drama in an Inquiry-Based Elementary Program: The Effect on Student Attitude and Conceptual Learning. Journal of Science Teacher Education, 23, 823-846. http://dx.doi.org/10.1007/s10972012-9292-1 